\title{
Some Observations of Ausageing Effects on the Martensitic Transformation in an Fe-Ni-Ti Alloy*
}

\author{
By Tsugio Tadaki**, Kyoichiro Asayama*** and Ken'ichi Shimizu**
}

\begin{abstract}
The martensitic transformation in an Fe-30.0Ni-3.8Ti (mass \%) alloy ausaged at $973 \mathrm{~K}$ for various periods has been examined by means of optical as well as transmission electron microscopy, electron as well as X-ray diffraction and electrical resistivity-temperature measurements. While the martensites in the unaged specimens were lenticular in shape as those in Fe-Ni binary alloys, those in the specimens ausaged for longer periods were of thin plate to a great extent, when formed at temperatures near the $M_{\mathrm{s}}$, though the $M_{\mathrm{s}}$ temperature became considerably higher than that of the unaged specimens. Some of the thin plate martensites grew in the sidewise as well as the lengthwise directions and eventually became lenticular upon cooling to lower sub-zero temperature, the newly produced martensites during the sub-zero cooling being also lenticular. In addition, the thin plate martensites were so unique that twinned regions were hardly observed inside. The crystal structure of the martensite was tetragonal with $c / a=1.02$ in the unaged state. The tetragonality rapidly increased a little to 1.03 after short ausageings, but it diminished to almost unity after prolonged ausageings.

The morphological change of martensites associated with ausageing and sub-zero cooling was discussed together with the peculiar austenite stabilization phenomenon previously reported.
\end{abstract}

(Received July 15, 1983)

Keyzerds: iron-nickel-titanium alloy, martensitic transformation, ausageing, electron microscopy, crystal structure, martensite morphology

\section{Introduction}

The martensitic transformations in $\mathrm{Fe}-\mathrm{Ni}-\mathrm{Ti}$ or -Al alloys are known to be greatly influenced by ausageing, as to the transformation temperature, $M_{\mathrm{s}}$, and the tetragonality (or the crystal structure), the morphology and the substructure of the product martensites ${ }^{(1)-(11)}$. Various influences of ausageing have been studied in $\mathrm{Ni}_{3} \mathrm{Ti}$ (or $\mathrm{Ni}_{3} \mathrm{Al}$ ) $\left(\gamma^{\prime}\right)$ particles having a $\mathrm{Ll}_{2}$ type superlattice structure $^{(2)(3)}$ or small clusters ${ }^{(8)}$ of solute atoms, which have been verified or supposed to be formed upon ausageing, respectively. But, how the $\gamma^{\prime}$ particles or the clusters affect the martensitic transformations in those alloys is not definitely understood yet. In order

* This paper was originally presented at the Annual Fall Meeting of the Japan Institute of Metals, Sapporo, (1982).

** The Institute of Scientific and Industrial Research, Osaka, University, 8-1 Mihoga-oka, Ibaraki, Osaka 567, Japan.

*** Graduate Student, Osaka University, Osaka. Present address: Hitachi Research Laboratory, Hitachi Ltd., 4026 Kujicho, Hitachi, Ibaraki 319-12, Japan. to make it clear, the present authors have examined the overall aspects of the changes in transformation behavior upon ausageing of an $\mathrm{Fe}-\mathrm{Ni}-\mathrm{Ti}$ alloy, which has a composition similar to that of the alloy formerly studied in some detail by Abraham and Pascover ${ }^{(3)}$, by means of optical as well as transmission electron (TEM) microscopy, electron as well as X-ray diffraction and electrical resistivity-temperature measurements. In consequence, some interesting results have been obtained, one of which is a peculiar austenite stabilization phenomenon as already described very briefly ${ }^{(12)}$. The purpose of the present paper is to report these results in some detail.

\section{Experimental Procedures}

An $\mathrm{Fe}-30.0 \mathrm{Ni}-3.8 \mathrm{Ti}$ (mass \%) (chemically analysed composition) alloy ingot was made by vacuum casting after vacuum melting of electrolytic iron (99.9\%), Mond nickel (99.97\%) and sponge titanium $(99.7 \%)$ in a zirconia crucible. After being hot-forged, the ingot was homogenized at $1473 \mathrm{~K}$ for $86.4 \mathrm{ks}$ in an evacuated quartz tube, and then hot- and cold- 
rolled to a sheet $1 \mathrm{~mm}$ in thickness. Specimens $1 \mathrm{~mm} \times 5^{2} \mathrm{~mm}^{2}$ and $1 \mathrm{~mm} \times 20^{2} \mathrm{~mm}^{2}$ in size were cut from the sheet for optical microscopy and X-ray diffraction, respectively. The residual of the sheet was further cold-rolled to $0.2 \mathrm{~mm}$ in thickness, from which specimens for electrical resistivity-temperature measurements $(0.2 \mathrm{~mm}$ $\times 2 \mathrm{~mm} \times 20 \mathrm{~mm})$ and TEM $(0.2 \mathrm{~mm} \times \phi 3 \mathrm{~mm})$ were cut. All the specimens were solutiontreated at $1473 \mathrm{~K}$ for $7.2 \mathrm{ks}$ in evacuated quartz tubes, and then quenched into iced water, the tubes not being broken. Subsequently, various ausageing treatments were done at $973 \mathrm{~K}$ for periods ranging from 0 to $57.6 \mathrm{ks}$ in sealed quartz tubes back filled with argon. TEM observations were carried out at room temperature by using a $500 \mathrm{kV}$ electron microscope (HU-650).

\section{Results}

\section{Precipitation reactions occurring upon ausageing}

Upon the ausageing at $973 \mathrm{~K}$, two different types of precipitation reactions were observed to concurrently occur, in accordance with previous reports. One was a grain boundary reaction along austenite grain boundaries ${ }^{(13)}$, and the other a precipitation reaction inside the austenite grains $^{(1)}$.

The former reaction becomes easily appreci- able in an optical microscopic scale, as shown in Fig. 1; the reacting region occupies almost one half of the specimen volume after $57.6 \mathrm{ks}$ ausageing (see $\left.(d)^{\dagger}\right)$. The reaction products were confirmed by TEM to consist of lamellae of the $\mathrm{Ni}_{3} \mathrm{Ti}\left(\mathrm{DO}_{24}\right.$ type) phase and a $\mathrm{BCC}$ one ${ }^{(14)}$. In spite of the salient grain boundary reaction, an X-ray diffraction experiment showed that the lattice parameter of the retained austenite hardly changed with ageing time; the lattice parameter determined was, for example, 0.359 and $0.358 \mathrm{~nm}$ for unaged and $57.6 \mathrm{ks}$ ausaged specimens, respectively. This result implies that the solute concentration in the austenite matrix remains constant during the ausageing for periods up to $57.6 \mathrm{ks}$, and therefore, that local changes in the solute concentration in the lamellae are almost completely compensated inside. Consequently, it appears that the grain boundary reaction itself, despite the outstanding appearances of the products, may not significantly affect the martensitic transformation.

In the austenite matrix, on the other hand, very fine precipitates were observed after the ausageing, being uniformly dispersed. The precipitates gradually grew with ageing time, as

$\dagger$ In Fig. 1(d) as well as (c), some martensite plates are observed inside the austenite grains besides the grain boundary precipitates, because $M_{\mathrm{s}}$ is raised to near room temperature, as will be shown later.

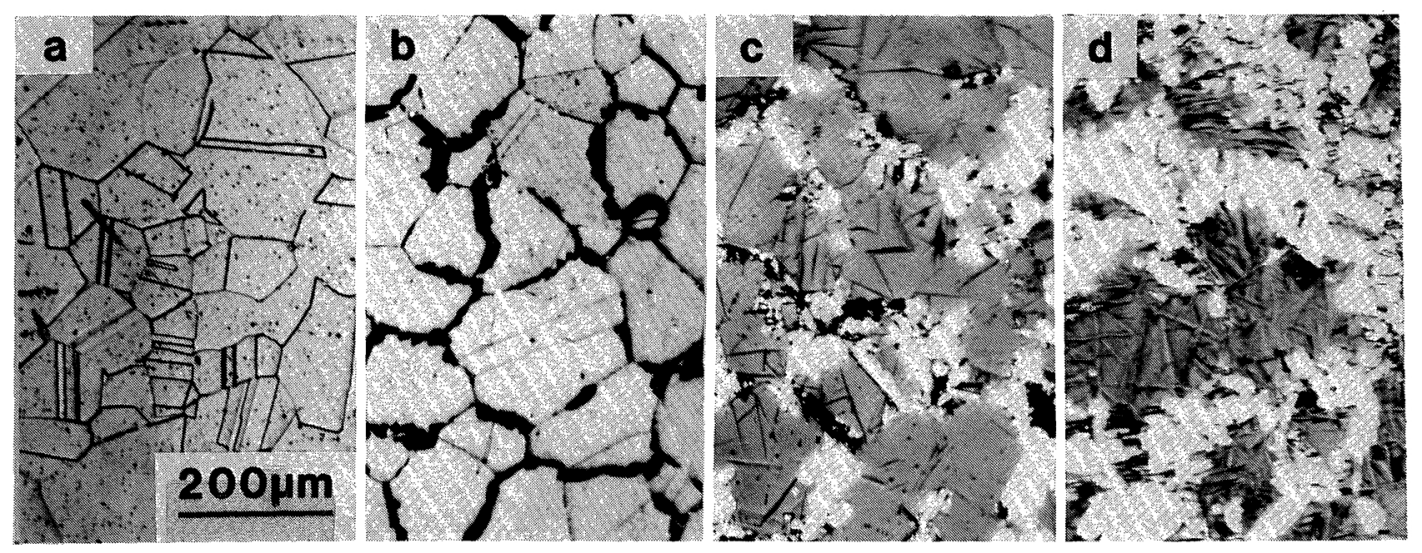

Fig. 1 Optical micrographs showing a grain boundary reaction along austenite grain boundaries in an $\mathrm{Fe}-30.0 \mathrm{Ni}-3.8 \mathrm{Ti}$ (mass \%) alloy, caused by ausageing at $973 \mathrm{~K}$ for 0 , i.e., unaged (a), $1.8 \mathrm{ks} \mathrm{(b),} 28.8 \mathrm{ks}$ (c) and $57.6 \mathrm{ks}$ (d). 


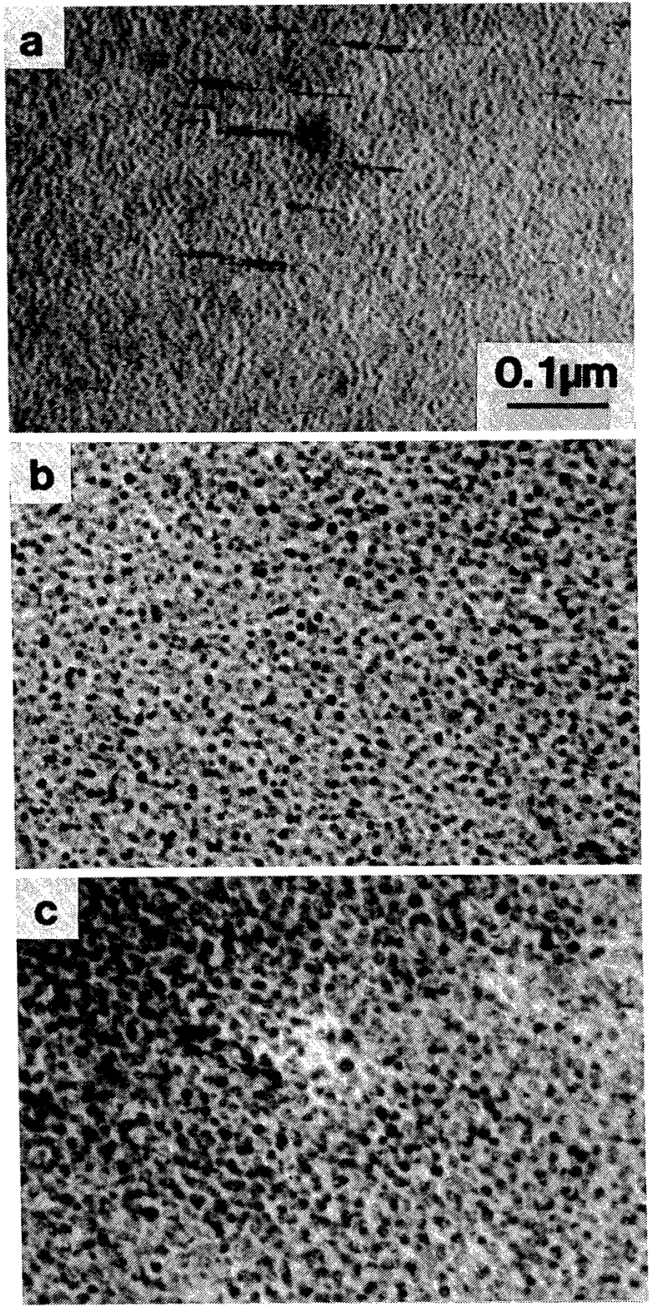

Fig. 2 Transmission electron micrographs showing a continuous precipitation reaction inside austenite grains, caused by ausageing at $973 \mathrm{~K}$ for $3.6 \mathrm{ks}$ (a), $28.8 \mathrm{ks}$ (b) and $57.6 \mathrm{ks}$ (c). All the micrographs were taken from martensitic regions in thin foil specimens.

shown in Fig. 2. Average sizes of the precipitates were roughly estimated to be 5,10 and $15 \mathrm{~nm}$ in diameter for $3.6,28.8$ and $57.6 \mathrm{ks}$ ausaged specimens, respectively. The precipitates were confirmed by electron diffraction to be of the $\gamma^{\prime}$ having a $\mathrm{Ll}_{2}$ type superlattice structure ${ }^{(3)}$. Since no obvious splittings of fundamental reflections are observed in electron diffraction patterns taken from the austenite, the $\gamma^{\prime}$ precipitates are considered to have a lattice parameter very close to that of the sur- rounding austenite matrix, and thus to be coherent with it, as previously reported ${ }^{(3)}$. It appears that such fine precipitates are essentially responsible for various changes in the transformation behavior brought about by ausageing, such as those described below.

\section{Variation of $M_{s}$ temperature}

The variation of $M_{\mathrm{s}}$ determined from electrical resistivity-temperature measurements ${ }^{(12)}$ is shown in Fig. 3 as a function of ageing time; the $M_{\mathrm{s}}$ only increases with increasing ageing time and never decreases to a value below that of unaged specimens. As already pointed out $^{(12)}$, this result is in contrast to a former result by Abraham and Pascover ${ }^{(3)}$ on an $\mathrm{Fe}-30.7 \mathrm{Ni}-3.6 \mathrm{Ti}$ (mass \%) alloy. According to them, $M_{\mathrm{s}}$ fell to a value below $77 \mathrm{~K}$ at the early stages of ageing at around $973 \mathrm{~K}$. However, it is very interesting to see the optical micrographs shown in Fig. 4, which were all taken at room temperature after ausageing for various periods and then sub-zero cooling to $77 \mathrm{~K}$. It is obvious that the martensitic transformation is significantly suppressed in (b), volume fraction of the martensite being roughly estimated to be $10 \%$. This means that the austenite is in fact stabilized at the early stage of ausageing, if a decrease of the amount of martensite is adopted as a criterion for the austenite stabilization in stead of a decrease of $M_{\mathrm{s}}$. In this meaning, the present result is in agreement with the previous report ${ }^{(3)}$.

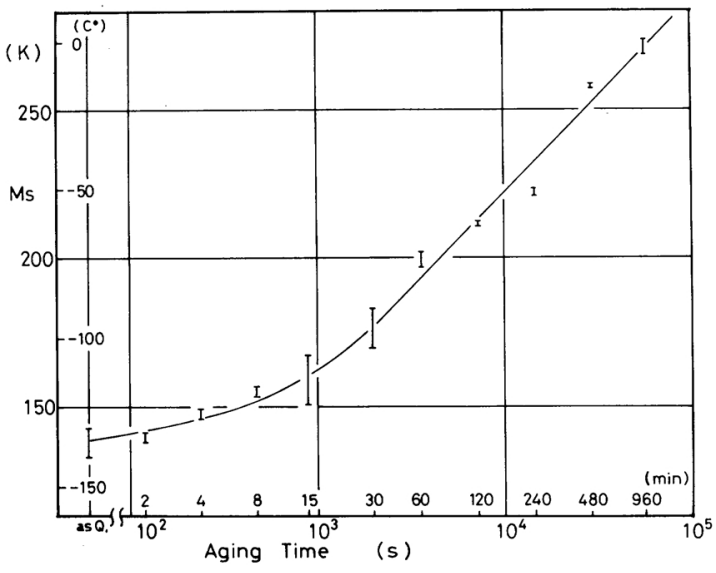

Fig. 3 Variation of $M_{\mathrm{s}}$ upon ausageing at $973 \mathrm{~K}$, as a function of ageing time. 

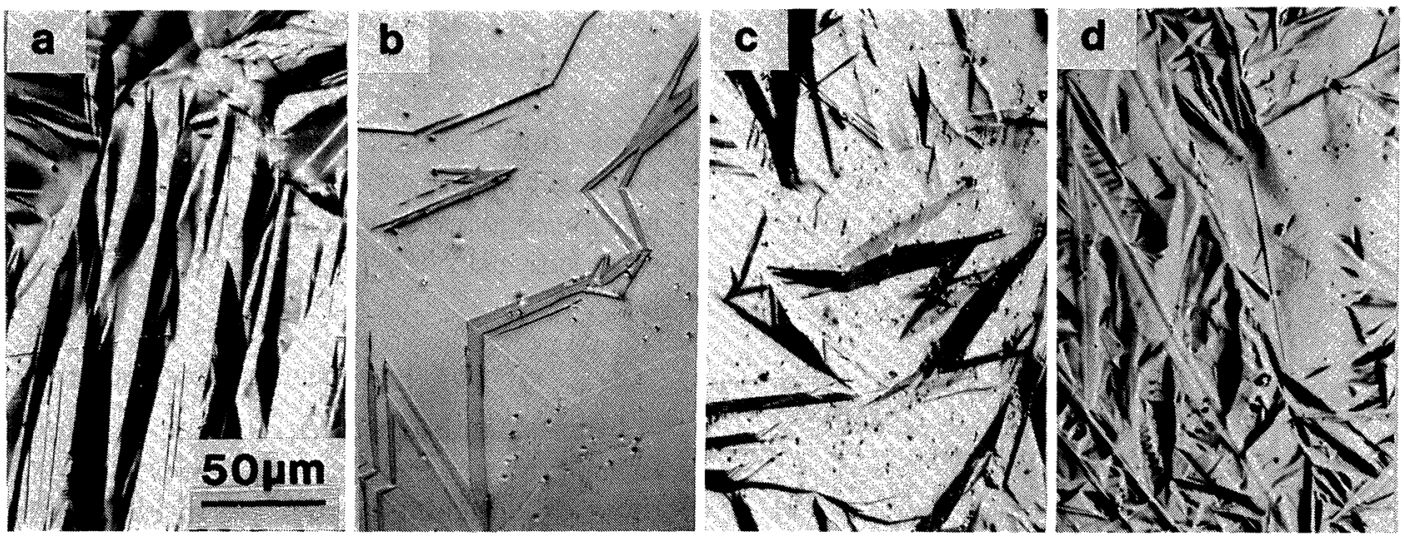

Fig. 4 Optical micrographs showing martensitic structures in the specimens ausaged at $973 \mathrm{~K}$ for 0, i.e., unaged (a), $240 \mathrm{~s} \mathrm{(b),} 1.8 \mathrm{ks}$ (c) and $28.8 \mathrm{ks}$ (d), and then sub-zero cooled to $77 \mathrm{~K}$.

However, it is very curious that the amount of martensite decreases at a certain stage of ausageing despite increase in $M_{\mathrm{s}}$. A similar phenomenon as to the austenite stabilization has also been observed in an ausformed $\mathrm{Fe}-$ $\mathrm{Ni}-\mathrm{C}$ alloy by Tamura et al. ${ }^{(15)}$. But, the situations for the occurrence are quite different from each other. A possible explanation will be given later for the present austenite stabilization phenomenon.

\section{Morphological change of martensite}

Making comparison among martensite structures in Fig. 4, the martensite morphology in (b) is particularly different from the other ones; the martensite plates in (b) appear to be thinner, although some of them still have a midrib. Such a morphology of martensite plates is similar to that previously observed in an $\mathrm{Fe}-$ $\mathrm{Ni}-\mathrm{Ti}$ alloy ausaged for short periods at $1023 \mathrm{~K}^{(5)}$. The martensite morphology in specimens ausaged for longer periods, (c) and (d), is not so apparently different from that in (a), also exhibiting a lenticular shape. However, the lenticular shape of martensites in (c) and (d) is essentially different from that in (a), as will be verified below.

Figure 5 is a series of optical micrographs taken from a specimen ausaged for $28.8 \mathrm{ks}$ at room temperature after each sub-zero cooling to the temperatures indicated. In (a) are seen "thin plate" martensites similar to those typically observed in $\mathrm{Fe}-\mathrm{Ni}-\mathrm{C}$ alloys ${ }^{(16)}$. However, some of them grow upon further sub- zero cooling in the sidewise as well as the lengthwise directions, (b), and eventually become lenticular, (c) and (d). A similar growth behavior from thin plate to lenticular martensites upon further sub-zero cooling was previously observed in an $\mathrm{Fe}-\mathrm{Ni}-\mathrm{C}$ alloy ${ }^{(16)}$. Such a two step or gradual growth was never observed in unaged specimens as in $\mathrm{Fe}-\mathrm{Ni}$ binary alloys ${ }^{(16)}$. It is also to be noted in Fig. 5(c) and (d) that the martensites newly formed during further subzero cooling are lenticular in general. Thus, the martensites in specimens ausaged for longer periods appear to be of lenticular morphology similar to those in unaged specimens, provided that the specimens are cooled to $77 \mathrm{~K}$.

By the way, if thin plate martensites as in Fig. 5(a) are compared with lenticular ones as in Fig. 4(a), one would say that the martensite morphology changes from lenticular to thin plate by ausageing for a long period. However, the thin plate martensites grew into lenticular upon further sub-zero cooling, as verified above. This means that a definite conclusion may not be simply given for the morphological change, since both the ausageing period and the subzero cooling temperature are concerned in it. But, it is true at least that thin plate martensites are formed in ausaged specimens when cooled to temperatures not far below $M_{\mathrm{s}}$, which is still higher than that of unaged specimens.

The above observations on the martensite morphology are very interesting in the following points. The first is that in spite of the increase of $M_{\mathrm{s}}$ thin plate martensites become to be 

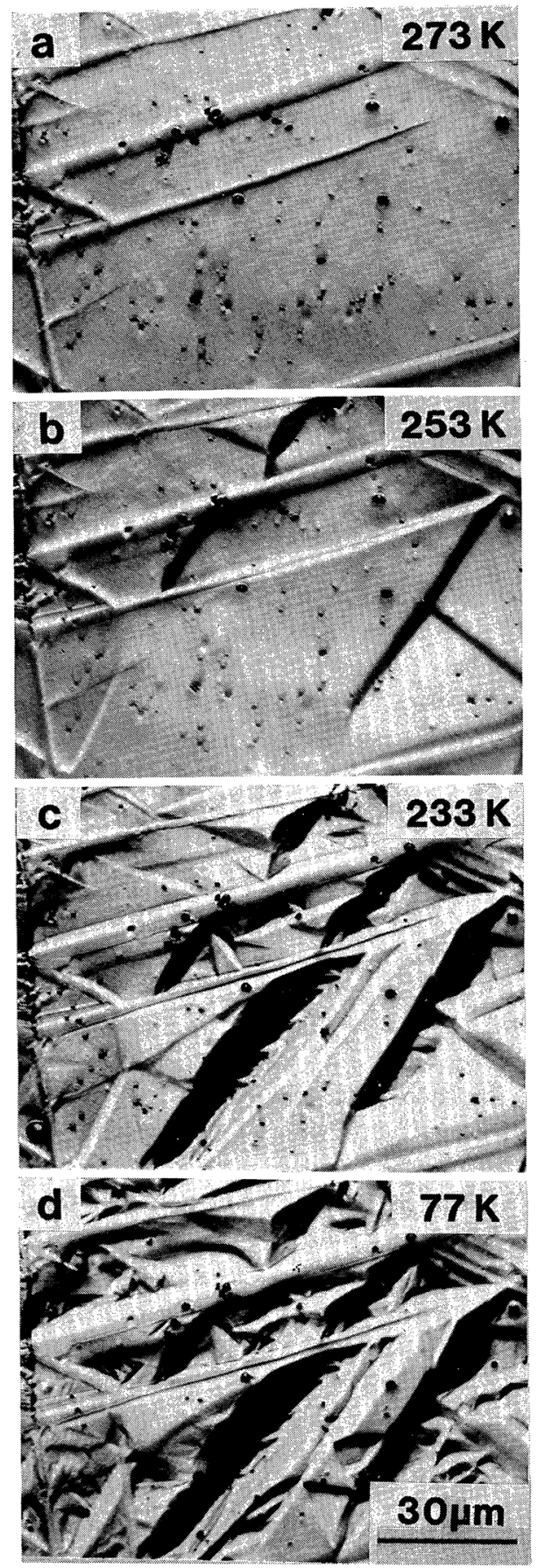

Fig. 5 A series of optical micrographs showing a morphological change of martensite upon successive sub-zero cooling. "Thin plate" martensites are seen to grow into lenticular with decreasing sub-zero temperature, and in addition newly produced ones to be also lenticular. formed by ausageing if the specimens are cooled to temperatures a little below the $M_{\mathrm{s}}$. The second is that the thin plate martensites grow into lenticular with further sub-zero cooling. These aspects as to the martensite morphology are obviously contrary to previous observations $^{(11)(17)(18)}$, as will be discussed later.

\section{Variation of martensite substructure}

Internal substructures of the martensites formed in unaged specimens were similar to those of lenticular martensites in $\mathrm{Fe}-\mathrm{Ni}$ alloys, partially twinned with a mid-rib, as previously reported ${ }^{(7)}$. The twinned regions were observed to become extremely localized in some lenticular martensites of the specimens subjected to prolonged ausageings and sub-zero cooling, as in an $\mathrm{Fe}-\mathrm{Ni}-\mathrm{Ti}-\mathrm{C}$ alloy ausaged for $3.6 \mathrm{ks}$ at $1073 \mathrm{~K}^{(7)}$. However, thin plate martensites are observed in the specimens cooled to a temperature somewhat lower than $M_{\mathrm{s}}$, and they are very unique; twinned regions were hardly observed inside. An example of such electron micrographs is shown in Fig. 6. The martensite seen in (a) is considered to correspond to one of the representative thin plate martensites as seen in Fig. 5(a). An effort to find some contrasts indicative of twin faults was made by tilting the thin foil specimens in the range of $\pm 10^{\circ}$, but resulted in failure. In addition, selected area electron diffraction patterns taken from the inside did not reveal any indication of the existence of twin faults. In (c), however, there are seen two sets of reflections with suffices $M_{1}$ and $\mathbf{M}_{2}$. Those were known merely to belong to two zones of the martensite, [731] and [951], away from each other by only about $6^{\circ}$. The simultaneous appearance of such two different zonal patterns is accounted for by some elongation of reciprocal lattice points, buckling of the foil specimen and so on. Anyway, such a nottwinned structure of the "thin plate" martensite is quite different from a completely twinned one of the thin plate martensites typically observed in $\mathrm{Fe}-\mathrm{Ni}-\mathrm{C}$ alloys ${ }^{(17)}$. Thus, another type of lattice invariant shear (LIS), other than twinning, should occur upon the formation of such a thin plate martensite as presently observed, in order to maintain the invariant plane 

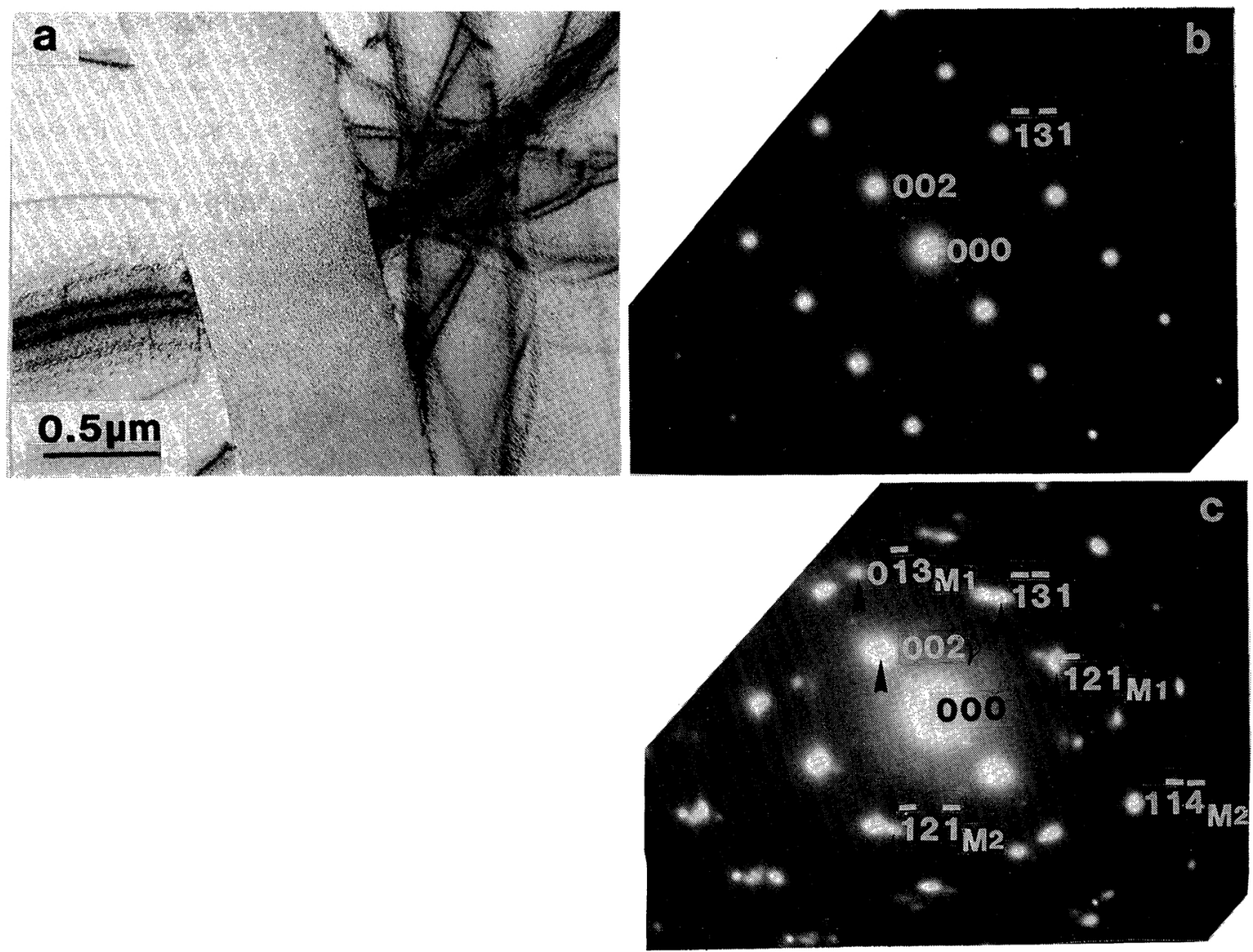

Fig. 6 Transmission electron micrograph of a "thin plate" martensite observed in a thin foil specimen ausaged at $973 \mathrm{~K}$ for $28.8 \mathrm{ks}$, (a), and electron diffraction patterns taken from the adjacent austenite matrix, (b), and the thin plate martensite, (c).

strain condition. But, what kind of LIS takes place in fact is not clear at present yet. Some stress relaxation processes around the $\gamma^{\prime}$ precipitates may possibly play an important role for the existence of invariant plane, habit plane, instead of internal twinning.

\section{Crystal structure change of martensite}

Figure 7 shows X-ray diffraction profiles obtained from the specimens ausaged for various periods indicated. The diffraction profiles were taken in the range of the scattering angle $2 \theta$ from $50^{\circ}$ to $54^{\circ}$, using Co $\mathrm{K}_{\alpha}$ radiation filtered with an Fe foil. Here, attention should be payed to the shape of the 110 martensite reflections around $52^{\circ}$ near the 111 austenite reflections around $51^{\circ}$. The 110 martensite reflections in (a) and (b) are obviously asymmetrical in shape, indicating the martensite crystal to be tetragonal. In fact, the $c / a$ axial ratios were estimated from the angles between split 211 reflections to be 1.02 and 1.03 for the unaged and $480 \mathrm{~s}$ ausaged specimens, respectively, being consistent with previous observations ${ }^{(6)(8)}$. Prolonged ausageings, however, resulted in somewhat broad but quite symmetrical 110 reflections, as seen in (c) and (d). This suggests that the martensite crystal changes from tetragonal to cubic. On the contrary, Lysak et al. ${ }^{(6)}$ previously proposed an orthorhombic structure whose maximum axial ratio was about 1.01 for the martensite in an $\mathrm{Fe}-31.2 \mathrm{Ni}-5.3 \mathrm{Ti}$ (mass \%) alloy ausaged at $973 \mathrm{~K}$ for about $64.8 \mathrm{ks}$. The reason for this discrepancy is not clear, but it may be accounted for by the difference in $\mathrm{Ti}$ concentration between the present and previous alloys. 

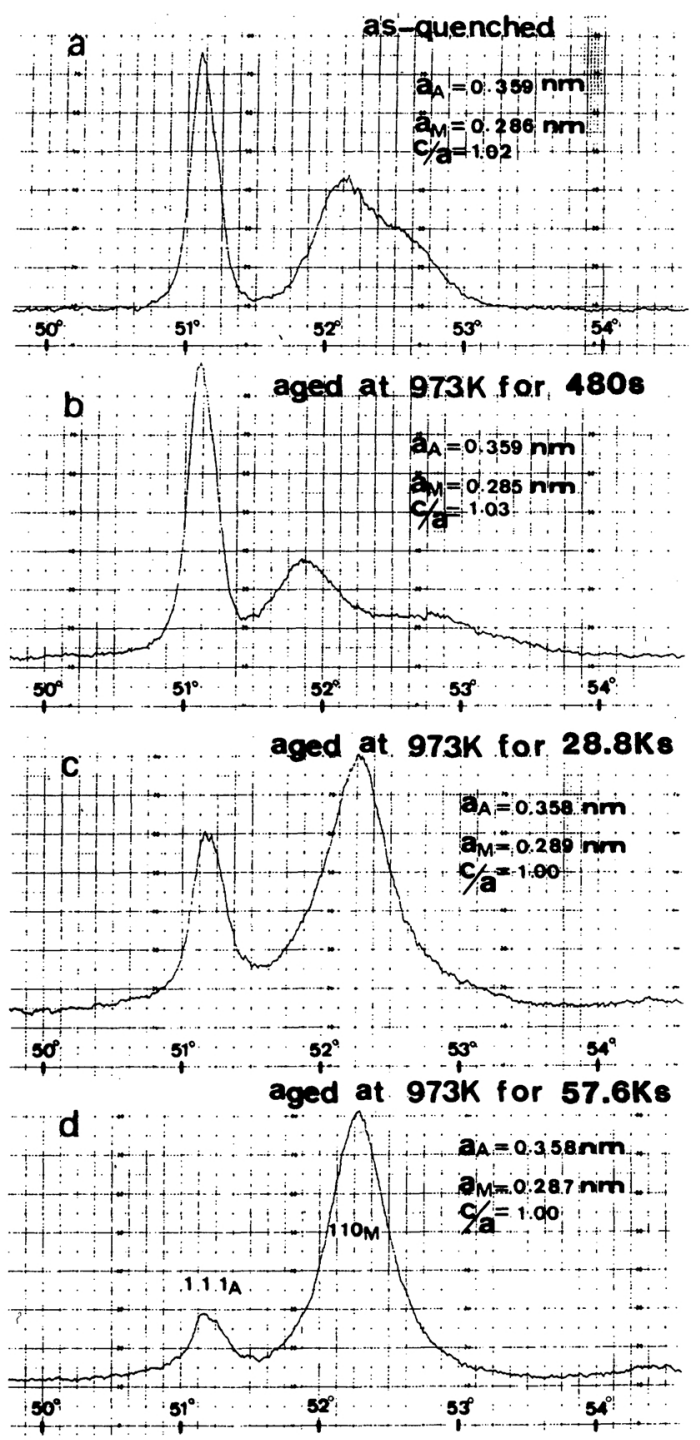

Fig. 7 X-ray diffraction profiles taken from the specimens ausaged at $973 \mathrm{~K}$ for various periods as indicated.

\section{Discussion}

\section{On the peculiar austenite stabilization phenomenon}

An increase of $M_{\mathrm{s}}$ upon ausageing has been observed in the present study. It is considered to be simply caused by a depletion of solute concentration caused by the formation of $\gamma^{\prime}$ precipitates in the austenite matrix. When the ageing temperature is so high as in the present experiment, the $\gamma^{\prime}$ precipitates may be considerably formed even at the very early stage of ausageing (possibly within $600 \mathrm{~s}^{(8)}$ ). The $\gamma^{\prime}$ precipitates may be preferentially formed at various kinds of lattice defects introduced upon quenching from the austenitizing temperature. Therefore, the lattice defects available for the nucleation site of martensitic transformation are supposed to be consumed by the formation of $\gamma^{\prime}$ precipitates to a great extent. If so, it may account for the decrease of the amount of martensite despite the increase of $M_{\mathrm{s}}$.

On the other hand, strain around the coherent interfaces between the $\gamma^{\prime}$ precipitates and austenite matrix may be increased, as the $\gamma^{\prime}$ precipitates grow. Besides the precipitation reaction in the austenite matrix, the cellular precipitation reaction simultaneously occurs at austenite grain boundaries, creating some imperfection around the incoherent interfaces between the cells and austenite matrix. These two kinds of interfaces are supposed to serve as active nucleation sites and to result in a gradual increase of the amount of martensites once decreased.

If the ageing period were extremely shortened or the ageing temperature were lowered by a few hundred degrees or so, clusters as proposed by Winchell et al. ${ }^{(8)(14)}$, i.e. $\mathrm{Ni}_{3} \mathrm{Ti}$ tetrahedrons, would possibly be formed in stead of the $\gamma^{\prime}$ precipitates. The formation of the clusters may not be accompanied by a significant depletion of solute concentration in the austenite matrix. But, a decrease of $M_{\mathrm{s}}$ would be caused, because an extra energy may be needed for the creation of strain fields which are expected when the clusters are inherited into martensites.

\section{On the martensite morphology}

Maki et al. ${ }^{(17)}$ previously found in $\mathrm{Fe}-\mathrm{Ni}-\mathrm{C}$ alloys that the martensite morphology changed from lenticular to thin plate even in an alloy with an identical composition if $M_{\mathrm{s}}$ temperature (or the formation temperature of martensites strain-induced) was decreased. Hence it has been known that a transition temperature exists for the morphological change of an individual alloy. Similar phenomena have also been found in Fe-Pt alloys by Umemoto and Wayman $^{(18)}$ and very recently in an $\mathrm{Fe}-\mathrm{Ni}$ - 
Ti-Co alloy by Maki et al. ${ }^{(11)}$. Thin plate martensites in those alloys were all completely twinned, that is, the transformation twins extended from one interface to the other, and accommodation slips were hardly observed in the surrounding austenite matrix. Accordingly, a high tetragonality of martensite (it may closely be related with easiness of twin formation), a high strength of austenite and small volume change during transformation were considered to be favorable factors for the appearance of internally twinned thin plate martensites ${ }^{(11)}$. The morphological transition from lenticular to thin plate with decreasing formation temperature were considered to be in a close relation with an increase of austenite strength due to its temperature dependence.

Thin plate martensites in the present alloy, however, appeared, as the $M_{\mathrm{s}}$ or the formation temperature became higher (see Fig. 5). Moreover, transformation twins were hardly observed inside. It thus appears that the martensite tetragonality and the austenite strength (at least the increase due to its temperature dependence) are less effective for the appearance of the present thin plate martensites. Volume change during transformation was estimated from the X-ray diffraction data to be $2.3 \%$ and $2.9 \%$ for the unaged and $28.8 \mathrm{ks}$ ausaged specimens, respectively. It is evident, therefore, that the volume change is not also an effective factor. The fact that the present thin plate martensites appeared when $M_{\mathrm{s}}$ or formation temperature was higher may probably be in a close relation with the absence of transformation twins. The formation mechanism of martensite may be different according to whether transformation twins are present or not. But, how the above aspects for the appearance of thin plate martensites can be accounted for by the absence of transformation twins is an open question at present.

\section{Conclusion}

In the present study, the martensitic transformation in an $\mathrm{Fe}-30.0 \mathrm{Ni}-3.8 \mathrm{Ti}$ (mass \%) alloy ausaged at $973 \mathrm{~K}$ for various periods has been examined morphologically and crystallographically. The results are summarized as follows:

(1) The grain boundary precipitation became remarkable upon ausageing, and the products came to occupy about one half of the specimen volume. Nevertheless, the lattice parameter and thus the solute concentration of the remaining austenite matrix was almost constant. Therefore, the grain boundary precipitation itself is considered not to significantly affect the martensitic transformation as to $M_{\mathrm{s}}$, morphology of martensite and so forth.

(2) $M_{\mathrm{s}}$ simply increased with ageing time, and never fell to below that of unaged specimens. This can be attributed to a depletion of solute concentration due to the $\gamma^{\prime}$ precipitation in the austenite matrix. Nevertheless, the amount of martensite significantly decreased at the early stage of ageing, and then normally increased with ageing time. This peculiar austenite stabilization phenomenon can be explained by a consumption of lattice defects available for the martensite nucleation because of a preferential nucleation of $\gamma^{\prime}$ precipitates at the defects.

(3) The martensites formed near $M_{\mathrm{s}}$ in ausaged specimens for longer periods were thin plate in shape to a great extent. Some of the thin plate martensites grew in the sidewise as well as lengthwise directions, and eventually became lenticular with decreasing sub-zero temperature, the newly produced martensites during the sub-zero cooling being also lenticular. These aspects on the appearances of thin plate and lenticular martensites are quite different from previous reports. The reason for this difference is not clear yet, but may probably be attributed to such a unique substructure of the present thin plate martensites as stated below.

(4) The thin plate martensites found in the present alloy were very unique in that twinned regions were hardly observed inside. It is suggested that some stress relaxation processes around the $\gamma^{\prime}$ precipitates in stead of internal twinning may possibly be involved during the transformation so as to maintain the well defined interface.

(5) The crystal structure of the martensite was tetragonal with $c / a=1.02$ in the unaged state. The tetragonality rapidly increased a little to 1.03 upon short ausageings and then 
diminished to almost unity upon prolonged ausageings.

\section{Acknowledgement}

The present study is partly supported by the Grant-in-Aid for Fundamental Scientific Research (Ippan A, 1980-81) from the Ministry of Education, Science and Culture of Japan, and the support is greatly appreciated.

\section{REFERENCES}

(1) R. K. Pitler and G. S. Ansell: Trans. ASM, 57 (1964), 220.

(2) E. Hornbogen and W. Meyer: Z. Metallk., 58 (1967), 373.

(3) J. K. Abraham and J. S. Pascover: Trans. Met. Soc. AIME, 245 (1969), 759.

(4) R. E. Miner: Met. Trans., 2 (1971), 1250.

(5) V. G. Gorbach, N. N. Kozyatnik, V. V. Kokorin, Yu. I. Samsonov and K. V. Chuistov: Fiz. Metal. Metalloved., 37 (1974), 580.

(6) L. I. Lysak, S. P. Kondrat'yev and V. S. Tatarchuk: Fiz. Metal. Metalloved., 42 (1976), 344.

(7) T. Maki and C. M. Wayman: Acta Met., 25
(1977), 695.

(8) M. M. Hall, P. G. Winchell and P. Guy: Acta Met., 25 (1977), 735.

(9) Yu. N. Koval', V. V. Kokorin and L. G. Khandros: Fiz. Metal. Metalloved., 48 (1979), 1309.

(10) M. Hayakawa and M. Oka: Reports of the Faculty of Engineering, Tottori Univ., 11 (1980), 22.

(11) T. Maki, K. Kobayashi and I. Tamura: Proc. ICOMAT-82, Supplemented to J. de Physique, (1982), p. C4-541.

(12) T. Tadaki, K. Asayama, T. Kakeshita and K. Shimizu: Scripta Met., 17 (1983), 893.

(13) G. R. Speich: Trans. Met. Soc. AIME, 22 (1963), 754.

(14) R. A. Fournelle: Acta Met., 27 (1979), 1135.

(15) I. Tamura, T. Maki, M. Nakanishi and Y. Oka: Suiyokwai-shi (Kyoto Univ.), 17 (1970), 75.

(16) T. Kakeshita, K. Shimizu, T. Maki and I. Tamura: Scripta Met., 14 (1980), 1067.

(17) T. Maki, S. Shimooka, S. Fujiwara and I. Tamura: Trans. JIM, 16 (1975), 35.

(18) M. Umemoto and C. M. Wayman: Acta Met., 26 (1978), 1529.

(19) P. G. Winchell and G. R. Speich: Acta Met., 18 (1970), 53. 